\title{
EFFECT OF ANNEALING ON LUMINESCENCE AND PHOTOCATALYTIC ACTIVITY OF ZNS NANOCRYSTALS UNDER UV LIGHT IRRADIATION
}

\author{
Hassan ALI, Milan MASAR, Michal URBANEK, Ali Can GULER, Pavel URBANEK, \\ Michal MACHOVSKY, Ivo KURITKA
}

Centre of Polymer Systems, Tomas Bata University in Zlin, Czech Republic, EU, hali@utb.cz

https://doi.org/10.37904/nanocon.2020.3707

\begin{abstract}
Zinc sulfide $(\mathrm{ZnS})$ nanocrystals were prepared at a large-scale via precipitation of $\mathrm{Zn}^{2+}$ ions water solution with gaseous hydrogen sulfide, $\mathrm{H}_{2} \mathrm{~S}$. The effect of annealing time on the $\mathrm{ZnS}$ phase structure, morphology, and optical properties was investigated in detail by XRD, SEM, UV-vis, and photoluminescence (PL) spectroscopy. It was observed that pristine $\mathrm{ZnS}$ possessed a pure cubic phase structure and an increase in annealing time resulted in a phase mixture with increased content of wurtzite phase structure. Moreover, the crystallinity of the prepared samples, as well as PL intensities, increased with increasing annealing time. Photocatalytic activities of the pristine $\mathrm{ZnS}$ annealed at different time intervals were evaluated by the means of methyl violet 2B (MV 2B) degradation under UV LED illumination wavelengths at $\lambda_{\max } \sim 343 \mathrm{~nm}$ and $365 \mathrm{~nm}$. It was observed that the photocatalytic activities of the annealed $\mathrm{ZnS}$ samples increased with increasing annealing time. The improved photocatalytic performance can be attributed to the improved crystallinity of annealed ZnS samples.
\end{abstract}

Keywords: ZnS, annealing, photocatalysis, luminescence

\section{INTRODUCTION}

Zinc sulfide $(Z n S)$ is an important wide bandgap semiconductor with optoelectronic properties suitable for diverse applications in light-emitting diodes (LEDs), electroluminescent flat panel displays, sensors, photovoltaic devices, photocatalysis, and water splitting [1,2]. Due to its luminescent properties, which were first recognized by Sidot in the $19^{\text {th }}$ century followed by the discovery of phosphor-based high field electroluminescence in 1936, ZnS is probably the most studied sulfide semiconductor material to date [3]. ZnS exists in two crystalline forms, i.e., cubic ZnS (sphalerite) and hexagonal ZnS (wurtzite) phase with an optical bandgap of $3.72 \mathrm{eV}$ and $3.77 \mathrm{eV}$ at room temperature, respectively. The wurtzite phase is thermodynamically metastable and forms at a higher temperature than sphalerite $\left(1020^{\circ} \mathrm{C}\right.$ in bulk $\left.\mathrm{ZnS}\right)$. Moreover, the crystallography of $\mathrm{ZnS}$ is complicated by its propensity to crystallize in a variety of polymorphic modifications and polytypes, with substantially deviated phase structures. Due to this extensive polytypism, defect structures associated with intergrowths of several crystal forms are commonly encountered [4]. These defects, together with native point defects are responsible for the luminescence even in pristine, undoped ZnS, especially when thermally post-treated. Although ZnS itself exhibits luminescence over a broad range of wavelengths, emission wavelength and intensity can be finely tuned by modifying its structural properties.

While $\mathrm{ZnS}$ is traditionally used in various electroluminescent devices, it has also been widely studied for its ability of water splitting and photocatalytic degradation of the pollutants. ZnS has been already demonstrated to possess excellent photocatalytic activity towards degradation of dyes, phenol, or halogenated compounds under UV light irradiation, as well as hydrogen evolution capability [5-8].

ZnS nanocrystals are typically synthesized by hot injection method or heat-up method, with both employing various types of precursors. The most commonly used method of hot injection can produce nanocrystal batches with good crystallinity and high PL quantum yields but there is a drawback of limited scalability. This 
restriction of large scale production is due to the inevitable occurrence of nucleation and growth stages at different temperatures and times [9-11]. Herein, we report a facile preparation method of nanocrystalline $\mathrm{ZnS}$, which is based on the precipitation of $\mathrm{Zn}^{2+}$ cations in an aqueous solution by gaseous hydrogen sulfide, $\mathrm{H}_{2} \mathrm{~S}$, at room temperature. The effect of annealing time on luminescence properties and photocatalytic activity was also investigated in detail.

\section{EXPERIMENTAL}

\subsection{Materials}

Zinc nitrate hexahydrate $\left(\mathrm{Zn}\left(\mathrm{NO}_{3}\right)_{2} .6 \mathrm{H}_{2} \mathrm{O}\right)$, sodium sulfide hydrate $\left(\mathrm{Na}_{2} \mathrm{~S} . \mathrm{xH}_{2} \mathrm{O}\right)$, hydrochloric acid $(\mathrm{HCl}, 38 \%$ aqueous solution) were all purchased from Sigma Aldrich (St. Louis MO, USA) and used as received without further purification.

\subsection{Synthesis of ZnS nanocrystals}

ZnS nanocrystals were synthesized by the precipitation of zinc ions by hydrogen sulfide at room temperature according to the method described previously for the preparation of CuS nanoplates by our group [12] as follows: $4.569 \mathrm{~g}$ of zinc nitrate hexahydrate was dissolved in $100 \mathrm{~mL}$ of water and transferred into a cylindrical flask. Afterward, the gaseous hydrogen sulfide evolved by the reaction of sodium sulfide with hydrochloric acid was bubbled through the solution containing zinc ions. During this, the solution $\mathrm{pH}$ increased steeply, and the precipitation reaction occurred in a short time interval after reaching $\mathrm{pH}$ high enough at which $\mathrm{S}^{2-}$ ions predominated in solution. The resultant white precipitate was washed several times by distilled water prior to filtration and the collected powder was dried in an oven at $60^{\circ} \mathrm{C}$. The obtained dried powder was later put into a glass test tube and annealed using a Bunsen burner for 30 and $90 \mathrm{~s}$. The glass test tube was placed within flame at the position of highest temperature, i.e., at the tip of the inner flame cone. The temperature of samples measured immediately following the annealing process by the contactless thermometer was approximately $350{ }^{\circ} \mathrm{C}$ and $700{ }^{\circ} \mathrm{C}$, for 30 and $90 \mathrm{~s}$, respectively. The annealed samples were labeled as ZnS-30 and ZnS90.

\subsection{Characterization methods}

The crystalline phases of the as-prepared samples were characterized by the X-ray diffractometer Miniflex 600 (Rigaku, Japan) with a Co-Ka X-ray source $(\lambda=1.5418 \AA)$ in the diffraction angle range $5-85^{\circ} 2 \theta$. The morphology was investigated by scanning electron microscope NOVA NanoSEM 450 (FEI, The Netherland). The study of UV-vis absorption of prepared powders was performed by the UV-vis spectrometer LAMBDA $1050+$ (PerkinElmer, UK). Photoluminescence (PL) measurements were carried out by fluorescence spectrometer FLS920 (Edinburgh Instruments Ltd).

\subsection{Photocatalytic experiment}

The photocatalytic activity of the as-prepared samples was evaluated via degradation of methyl violet $2 \mathrm{~B}$ (MV

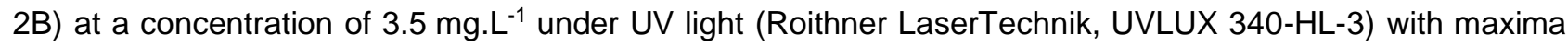
wavelength of 343 and $365 \mathrm{~nm}$. An original experimental arrangement intended for the online measurement of photocatalytic activity under irradiation with LED comprised of various wavelengths was used. It is based on the homemade cuvette holder housing equipped with LED mounted directly inside the UV-vis spectrometer. The cuvette serves as a miniature photochemical reactor with its content being mixed continuously or in a duty cycle with a small magnetically driven stirrer bar. In a typical experiment, a quartz glass cuvette containing 10 $\mathrm{mg}$ of photocatalyst and $5 \mathrm{~mL}$ of model dye solution was inserted inside the UV-vis spectrophotometer, covered by cuvette holder housing, and stirred in the dark for 1 hour in order to reach adsorption/desorption equilibrium. After that, an LED was switched on with continuous stirring. Degradation of model dye was monitored every 
15 minutes interval without the need for sampling and extra evaluation. During the experiment, the temperature was precisely controlled to $25^{\circ} \mathrm{C}$ by dual cell Peltier.

\section{RESULTS AND DISCUSSION}

The crystalline phase structures of the pristine ZnS powder and the products of its annealing were investigated by powder XRD. The diffractogram of pristine ZnS and the products of its annealing for 30 and 90 s are shown in Figure 1. XRD pattern of the pristine ZnS exhibits three peaks at diffraction angles $2 \theta=33.34^{\circ}, 55.86^{\circ}$ and $66.63^{\circ}$ which corresponds to most intense (111), (220) and (311) planes of the (sphalerite) cubic ZnS phase (PDF Card No.: 01-071-4763), respectively. The broadness and the low intensities of the peaks indicate small particle size and poor crystallinity. Phase quantification for the pristine and annealed samples was done by the RIR (reference intensity ratio) method and the calculated values are given in Table 1. It should be mentioned that the unambiguous identification of $\mathrm{ZnS}$ phase structures is accompanied by some difficulties, as both polymorphs possess tetrahedral arrangements of $\mathrm{Zn}$ and $\mathrm{S}$ and differ only in the stacking sequence of atomic layers in cubic and hexagonal structures. Based on the RIR calculation, even pristine ZnS is not composed entirely of cubic phase but contains about $10 \%$ of the wurtzite hexagonal phase. Average crystalline scattering domain sizes, $D_{c}$, were also estimated according to the well-known Debye-Scherrer formula and the values are given in Table 1.

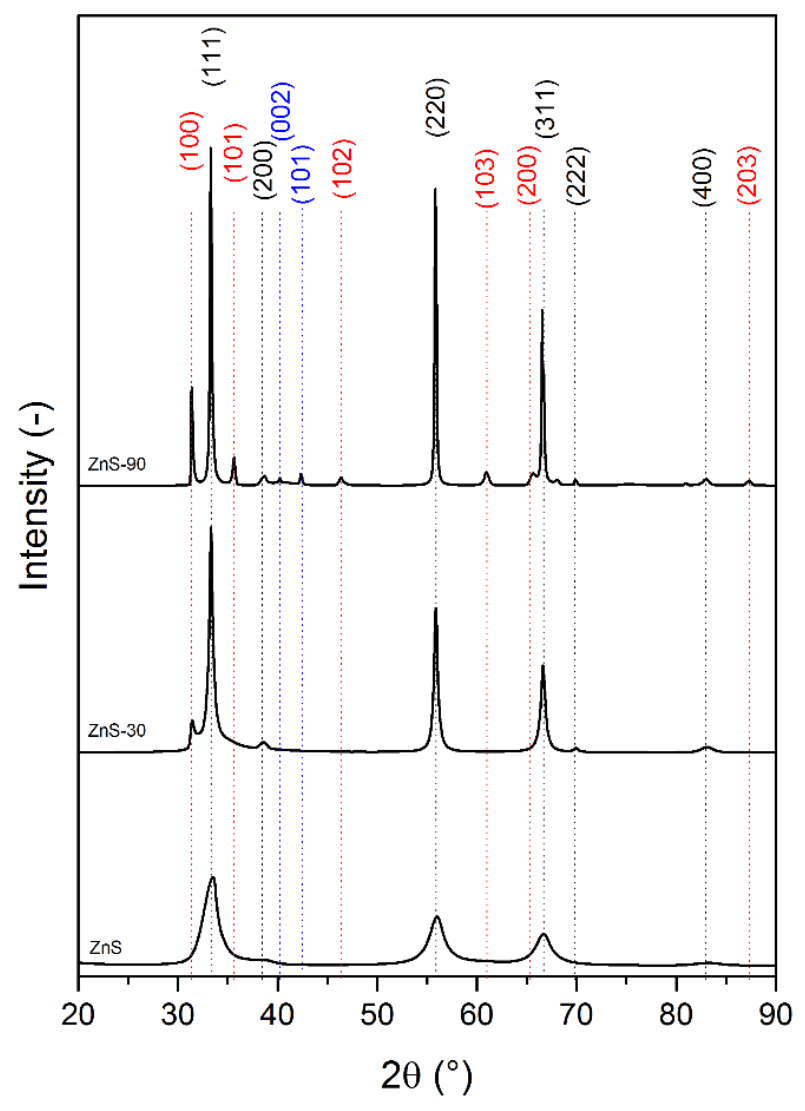

Figure 1 Powder XRD patterns of samples ZnS, ZnS-30, and ZnS-90. Stick pattern correspond to PDF Card No.: 01-071-4763 (sphalerite cubic phase ZnS, black), PDF Card No.: 00-036-1450 (wurtzite hexagonal ZnS, red), and PDF Card No.: 01-079-0207 (wurtzite hexagonal ZnO, blue)

The morphology of the as-prepared samples was investigated using SEM as shown in Figure 2. Pristine ZnS exhibits flake-like morphology with a smaller grain size, which is consistent with poor crystallinity as evidenced by the XRD results. For the annealed samples, ZnS-30 and Zn-90, an increase in the temperature led to 
coarser grain size. This increase may result in the extension of the absorption edge due to the formation of defects and scattering centers.
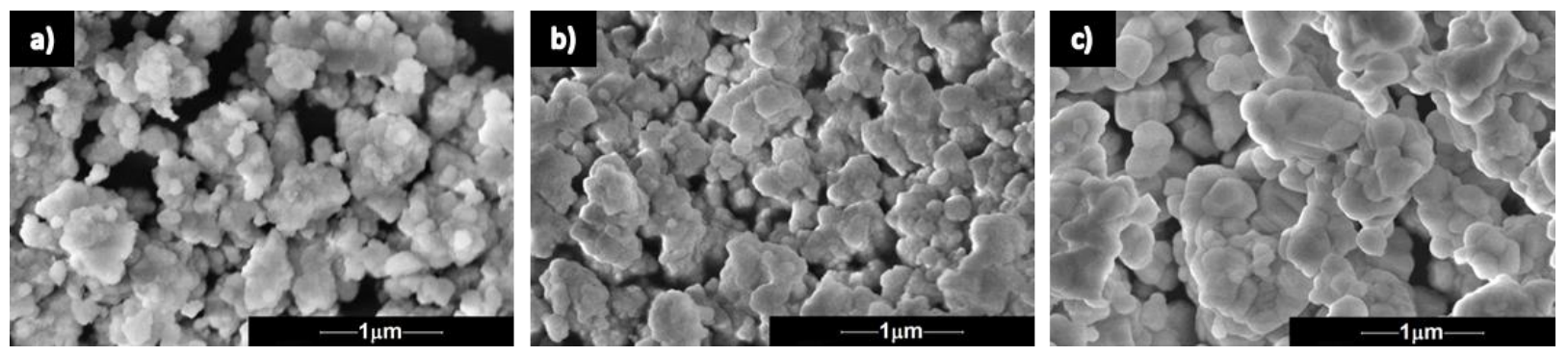

Figure 2 SEM images of precipitated ZnS (a) and products of its annealing for 30 and 90 s, ZnS-30 (b) ZnS90 (c)

Table 1 XRD data and photocatalytic activity of the prepared samples

\begin{tabular}{|c|c|c|c|c|c|c|}
\hline \multirow[b]{2}{*}{ Sample } & \multicolumn{3}{|c|}{ Crystalline phase structure } & \multirow{2}{*}{$\begin{array}{c}\text { Average } \\
\text { Crystallite size } \\
\text { [nm] }\end{array}$} & \multirow{2}{*}{$\begin{array}{l}\text { Rate Constant r, } \\
\lambda \sim 343 \mathrm{~nm}\left[\mathrm{~s}^{-1}\right]\end{array}$} & \multirow{2}{*}{$\begin{array}{l}\text { Rate Constant r, } \\
\lambda \sim 365 \mathrm{~nm}\left[\mathrm{~s}^{-1}\right]\end{array}$} \\
\hline & $\begin{array}{l}\text { Cubic } \\
\text { ZnS }\end{array}$ & $\begin{array}{c}\text { Hexagonal } \\
\text { ZnS }\end{array}$ & $\begin{array}{c}\text { Hexagonal } \\
\mathrm{ZnO} \\
\end{array}$ & & & \\
\hline $\mathrm{ZnS}$ & 90 & 10 & - & 6.2 & - & - \\
\hline ZnS-30 & 85 & 15 & - & 27.5 & $0.44 \pm 0.05$ & $0.09 \pm 0.01$ \\
\hline ZnS-90 & 62 & 35 & 3 & 64.0 & $0.94 \pm 0.03$ & $0.17 \pm 0.01$ \\
\hline
\end{tabular}

The photocatalytic activity of prepared materials was evaluated via degradation of $\mathrm{MV} 2 \mathrm{~B}$ at the concentration of $3.5 \mathrm{mg}$. L-1 under UV light irradiation (Roithner LaserTechnik, UVLUX 340-HL-3) with maxima wavelength of $343(3.6 \mathrm{eV})$ and $381 \mathrm{~nm}(3.4 \mathrm{eV})$. From Figure 3, it is obvious that the photocatalytic activity at 365 and $343 \mathrm{~nm}$ is greatest for the sample, ZnS-90. From Table 1, it can be seen that the rate constant for dye degradation with ZnS-90 sample is one-fold higher than for the sample ZnS-30, at both 365 and $343 \mathrm{~nm}$ light irradiation. The limited activity of ZnS-30 sample can be ascribed to the slow rate of electron-hole pairs creation and low crystallinity.

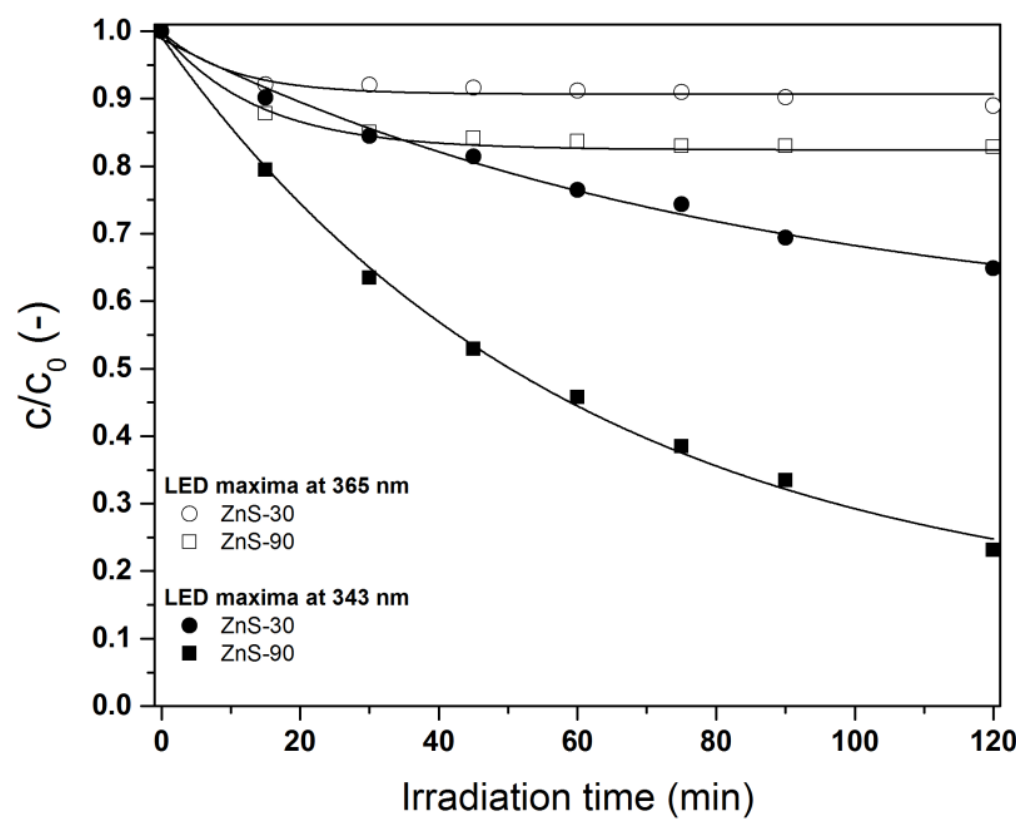

Figure 3 Photocatalytic activities of ZnS, ZnS-30, and ZnS-90 samples 
The as-prepared samples were also characterized by PL emission spectra to investigate the charge carrier's separation and recombination rate. A stronger intensity of $\mathrm{PL}$ indicates more rapid recombination of photoexcited electro-hole pairs while a lower PL intensity is associated with slow charge recombination rate. From Figure 4, it can be seen that pristine ZnS and ZnS-30, exhibit the lowest PL intensity while ZnS-90 has the highest $P L$ intensity implying that pristine $Z n S$ has a low recombination rate as compared to annealed $Z n S$ samples. This result indicates that the high photocatalytic activity of $Z n S-90$ sample is due to the rapid creation of electron-hole pairs which led to an increase in photocatalytic activity as compared to pristine $\mathrm{ZnS}$ and $\mathrm{ZnS}$ 30 samples.

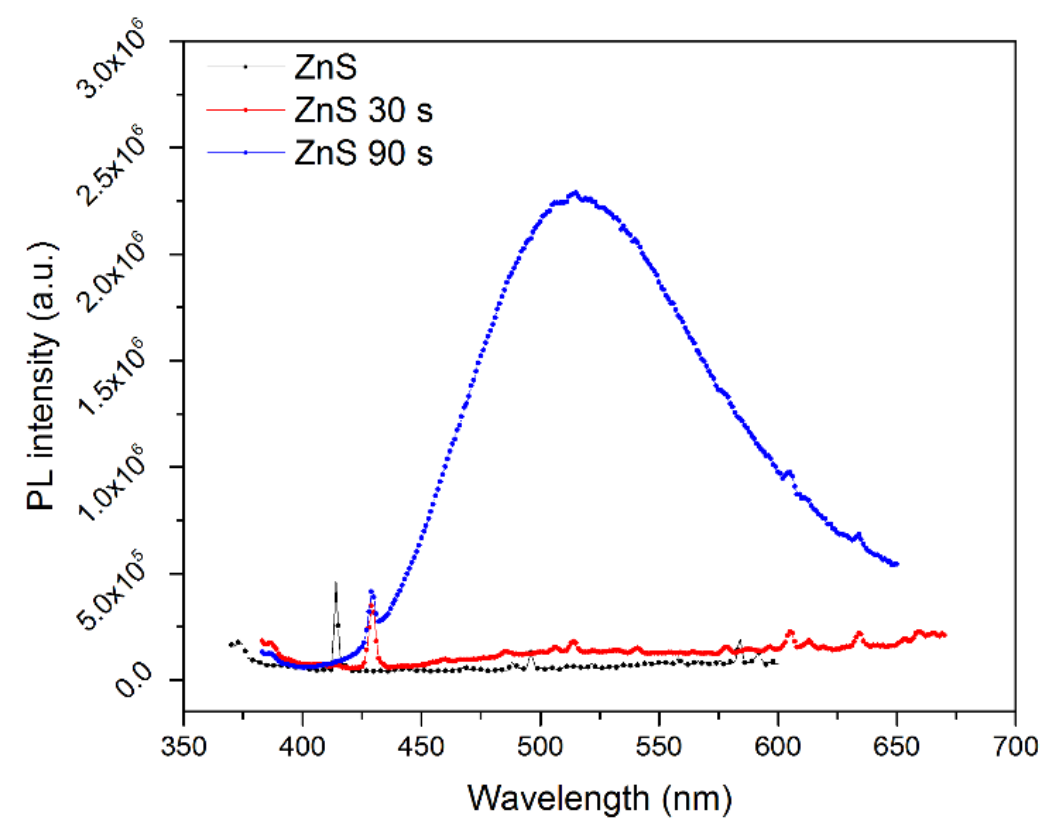

Figure 4 PL spectra for ZnS, ZnS-30 and ZnS-90 samples

\section{CONCLUSION}

ZnS nanocrystals were prepared and the effect of annealing on the ZnS phase structure, morphology, and optical properties was investigated. Pristine ZnS samples exhibited pure cubic phase structure with slight wurtzite content which increased with increasing annealing time. Pristine ZnS annealed for $90 \mathrm{~s}$ exhibited the highest photocatalytic activity as compared to unannealed ZnS. Optical investigation of the as-prepared samples suggested that annealing resulted in the formation of luminescence and charge recombination centers.

\section{ACKNOWLEDGEMENTS}

This research obtained funding from the Ministry of Education, Youth and Sports of the Czech Republic in the frame of the project LTT20010. This article was also written with the support of Operational Program Research and Development for Innovations co-funded by the European Regional Development Fund (ERDF) and the national budget of Czech Republic, within the framework of project CPS - strengthening research capacity (reg. number: CZ.1.05/2.1.00/19.0409). The work was also supported by the Internal Grant Agency of Tomas Bata University in Zlin; contract grant number: IGA/CPS/2017/007. This work was supported by the Ministry of Education, Youth and Sports of the Czech Republic - Program NPU I (LO1504). 


\section{REFERENCES}

[1] UMMARTYOTIN, S, BUNNAK, N, JUNTARO, J, SAIN, M, MANUSPIYA, H. Synthesis and luminescence properties of ZnS and metal (Mn, Cu)-doped-ZnS ceramic powder. Solid State Sci. 2012, vol. 14, no. 3, pp. 299304.

[2] FANG, X, ZHAI, T, GAUTAM, UK, LI, L, WU, L, BANDO, Y, et al. ZnS nanostructures: From synthesis to applications. Prog Mater Sci. 2011, vol. 56, no. 2, pp. 175-287.

[3] SMET, PF, MOREELS, I, HENS, Z, POELMAN, D. Luminescence in Sulfides: A Rich History and a Bright Future. Materials. 2010, vol. 3, no. 4, pp. 2834-2883.

[4] DENZLER, D, OLSCHEWSKI, M, SATTLER, K. Luminescence studies of localized gap states in colloidal ZnS nanocrystals. J Appl Phys. 1998, vol. 84, no. 5, pp. 2841-5.

[5] CHEN, F, CAO, Y, JIA, D. Facile synthesis of ZnS nanoparticles and their excellent photocatalytic performance. Ceram Int. 2015, vol. 41, no. 5, Part A, pp. 6645-52.

[6] PALANISAMY, VK, MANOHARAN, K, RAMAN, K, SUNDARAM, R. Efficient sunlight-driven photocatalytic behavior of zinc sulfide nanorods towards Rose Bengal degradation. J Mater Sci Mater Electron. 2020, vol. 31, pp. 14795-14809.

[7] HOJAMBERDIEV, M, CZECH, B, GÖKTAŞ, A.C., YUBUTA, K, KADIROVA, Z.C. SnO2@ZnS photocatalyst with enhanced photocatalytic activity for the degradation of selected pharmaceuticals and personal care products in model wastewater. J Alloys Compd. 2020, vol. 827, p. 154339.

[8] ZHOU, J, ZHAO, J, LIU, R. Defect engineering of zeolite imidazole framework derived ZnS nanosheets towards enhanced visible light driven photocatalytic hydrogen production. Appl Catal B Environ. 2020, vol. 278, p. 119265.

[9] MUNRO, AM. Synthetic approaches for growing zinc sulfide and zinc selenide colloidal nanocrystals. J Vac Sci Technol A. 2020, vol. 38, p. 020805.

[10] FLAMEE, S, CIRILLO, M, ABE, S, DE NOLF, K, GOMES, R, AUBERT, T, et al. Fast, high yield, and high solid loading synthesis of metal selenide nanocrystals. Chem Mater. 2013, vol. 25, no. 12, pp. 2476-2483.

[11] BANSKI, M, AFZAAL, M, MALIK, MA, PODHORODECKI, A, MISIEWICZ, J, O'BRIEN, P. Special Role for Zinc Stearate and Octadecene in the Synthesis of Luminescent ZnSe Nanocrystals. Chem Mater. 2015, vol. 27 , no. 11, pp. 3797-3800.

[12] MASAR, M, URBANEK, M, URBANEK, P, MACHOVSKA, Z, MASLIK, J, YADAV, RS, et al. Synthesis, characterization and examination of photocatalytic performance of hexagonal covellite CuS nanoplates. Mater Chem Phys. 2019, vol. 237, p. 121823. 